\title{
DÜBLIN
}

Technological University Dublin

ARROW@TU Dublin

\section{Orange Juices Enriched with Chitosan: Optimisation for Extending the Shelf-life}

\author{
Catherine Barry-Ryan \\ Technological University Dublin, Catherine.Barryryan@tudublin.ie \\ Ana Belen Martin-Diana \\ Technological University Dublin, anabelen.martindiana@tudublin.ie \\ Daniel Rico \\ Technological University Dublin, daniel.rico@tudublin.ie
}

See next page for additional authors

Follow this and additional works at: https://arrow.tudublin.ie/schfsehart

Part of the Food Science Commons

\section{Recommended Citation}

Martin-Diana, A. et al. (2009) Orange juices enriched with chitosan: Optimisation for extending the shelflife. Innovative Food Science and Emerging Technologies, 10 (2009), pp.590-600 doi :10.1016/ j.ifset.2009.05.003

This Article is brought to you for free and open access by the School of Food Science and Environmental Health at ARROW@TU Dublin. It has been accepted for inclusion in Articles by an authorized administrator of ARROW@TU Dublin. For more information, please contact arrow.admin@tudublin.ie, aisling.coyne@tudublin.ie, gerard.connolly@tudublin.ie.

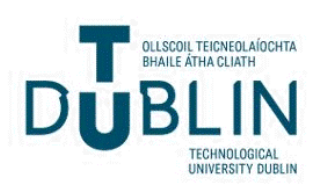


Authors

Catherine Barry-Ryan, Ana Belen Martin-Diana, Daniel Rico, and J. Barat

This article is available at ARROW@TU Dublin: https://arrow.tudublin.ie/schfsehart/21 


\title{
Orange juices enriched with chitosan: Optimisation for extending the shelf-life
}

\author{
Innovative Food Science and Emerging Technologies 10 (2009) 590-600
}

\author{
A. B. Martín-Diana 1, D. Rico 1, J.M. Barat 2, Catherine Barry-Ryan 1 \\ 1. School of Food Science and Environmental Health, Dublin Institute of Technology (DIT), Cathal Brugha Street, \\ Dublin 1, Ireland \\ 2. Institute of Food Engineering for Development, Department of Food Technology, Universidad Politécnica, \\ Camino de Vera s/n, 46022, Valencia, Spain
}

Keywords: Chitosan, Orange juice, Quality, Spoilage

\begin{abstract}
Optimisation of the incorporation of chitosan in orange juice was accomplished by the evaluation of quality and nutritional markers. Response surface methodology was applied to obtain quadratic and second degree response surface model equations. The analyses showed that increases in chitosan concentration extended the quality of the orange juice significantly ( $\mathrm{p}$ b 0.05), reducing enzymatic and non-enzymatic browning and controlling the spoilage during the storage time; however, concentrations $\mathrm{N} 1 \mathrm{~g} \mathrm{~L}-1$ produced a significant ( $\mathrm{p} \mathrm{N} \mathrm{0.05)} \mathrm{reduction} \mathrm{in} \mathrm{the} \mathrm{concentrations} \mathrm{of} \mathrm{ascorbic} \mathrm{acid} \mathrm{and} \mathrm{carotenoids} \mathrm{associated} \mathrm{with} \mathrm{the} \mathrm{positive} \mathrm{charge}$ of chitosan and its ability to flocculate and coagulate negatively charged substances. Also, concentrations $\mathrm{N} 1 \mathrm{~g} \mathrm{~L}-1$ were scored as unacceptable for the sensory panel due to an increase in bitterness. The study recommends the use of chitosan at concentrations up to $1 \mathrm{~g} \mathrm{~L}-1$ to extend quality and preserve ascorbic acid and carotenoids during storage time of fresh orange juice, thus avoiding the use of standard thermal treatments which produces a negative impact on the nutritional value.

Industrial relevance: One of the major problems of fresh orange juice is its limited shelf-life. Spoilage and quick degradation of vitamins are two of the most important causes of quality loss during the shelf-life of this product. Moreover, the U. S. Food and Drug Administration issued a warning to consumers against drinking unpasteurised orange juice products because of the potential contamination with Salmonella typhimurium and its association with an outbreak of human disease caused by this organism [FDA issues nationwide health alert on Orchid Island unpasteurised orange juice. Products Recalls, Market Withdrawals and Safety Alerts.]. The main objective of this study was the study of chitosan as a natural preservative for extending the shelf-life of orange juice and as an alternative to pasteurisation.
\end{abstract}

\section{Introduction}

The consumption of foods that promotes a state of well-being, better health and reduction of the risk of diseases has become popular as the consumer is becoming more health conscious. In this sense, there has been a lot of attention paid to specific types of dietary carbohydrates, namely the non-digestible oligosaccharides (NDO). In the food industry, these compounds have great potential to improve the quality of many foods, providing modifications to food flavour and improving physicochemical and biological properties of the final product.

Chitosan is obtained by deacetylation of chitin, a natural nondigestible oligosaccharide which is the main component of the cell walls of fungi, and the exoskeletons of arthropods and insects, being one of the most abundant organic materials, second only to cellulose (Riccardo \& Muzzarelli, 1977). The positive ionic charge of chitosan gives it the ability to chemically bind fats, lipids and bile acids
(Prashanth \& Tharanathan, 2007). It is a biodegradable non-toxic polymer, and over the last several years, chitin and chitosan polymers, especially the latter, have gathered increasing attention as promising polymeric materials with interesting applications in the pharmaceutical, chemical and food industries. Application include enzyme immobilisation and purification, wastewater treatment, and novel food ingredient with binding, gelling, thickening and stabilising properties (Knorr, 1984; Wang, \& Chang, 1997).

The antimicrobial and antioxidant activities make this polymer very interesting as an ingredient for the development of functional foods. Consumers have become increasingly conscious of what they eat and aware of the nutritional value of foodstuffs. Furthermore, claims on products promising a variety of nutritional and health benefits for those who consume them are now commonplace on certain foodstuffs marketed in the European Union. Particularly fruit juices and healthy drinks have experienced substantial growth during the last decade. Orange juice is one of the most popular fruit juices marketed and probably the most recognised and accepted. The high commercial value of orange juice is due to its pleasant sensory qualities (i.e. odour, taste and colour) and particularly appreciated is the high content in vitamin C and natural antioxidants (Rapisarda, 
Bellomo, \& Intelisano, 2001; Bull et al., 2004; Rivas, Rodrigo, Martínez, Barbosa-Cánovas, \& Rodrigo, 2006). Unpasteurised orange juice is gaining popularity among consumers. The fastest growing types have been chilled and fresh juices. The juice drink sector offers considerable scope for suppliers to target specific consumer demand for different flavours, sugar levels, concerns about additives, fortification and vitamin content.

The greatest obstacle to commercial marketing of orange juice is the limited shelf-life (Watada, Ko, \& Minott, 1996; Ayhan, Yeom, Zhang, \& Min, 2001; Soliva-Fortuny \& Martín-Belloso, 2003; Cortés, Esteve, \& Frigola, 2008; Cortés, Esteve, Rodrigo, Torregrosa, \& Frígola, 2006). Microbial spoilage, off-flavours production and ascorbic acid degradation are three of the most important causes of quality loss during the shelf-life of this product. Moreover the Food and Drug Administration issued a warning to consumers against drinking unpasteurised orange juice products because of the potential contamination with Salmonella typhimurium and its association with an outbreak of human disease caused by this organism (FDA, 2005).

While thermal pasteurisation of orange juice significantly reduces the risk of foodborne disease, it can also reduce the nutrient content. For this reason the scientific community and food industry focus their attention on non-thermal emerging technologies and alternative novel treatments to control undesirable microorganisms with less adverse effects on quality (Rosenthal \& Silva, 1997; Cardello, Schutz, \& Lesher, 2007). High intensity pulsed electric fields (HIPEF) (Dunn, 2001; Martín-Belloso \& Elez-Martínez, 2005), pressure/temperature combinations (Crelier, Robert, \& Juillerat, 1999; Shook, Shellhammer, \& Schwartz, 2001; Fachin et al., 2003), high pressure (HP) or ultraviolet radiation (UV) (Tran, 2001; Tran \& Farid, 2002) among others have been explored in order to extend the shelf-life of fruit juice.

There is consumer preference for natural antimicrobials in food products which supports the development of minimally processed products and bioactive compound-enriched functional foods. Consumers have also become more critical to the use of artificial additives (Bruhn, 2000). Ohlsson (1994) suggests that minimal processing techniques have emerged to meet the challenge of replacing traditional methods of preservation whilst retaining nutritional and sensory quality. Since the current food market shows massive opportunities for functional health-enhancing juices, a study was undertaken to assess the effect of chitosan as a natural ingredient to extend the shelf-life and enhance the nutritional value of fresh orange juice. Response Surface Methodology (RSM) was used to model the effect of chitosan concentration and storage time on fresh orange juice. To provide a base of scientific knowledge and support the innovation and product development of new functional juices, assuring consumer protection was the main objective of this investigation squeezed juice was passed through a strainer (twice) to remove pulp and seeds. The filtrate was homogenised using a lab-scale homogeniser for 5 min at $4{ }^{\circ} \mathrm{C}$ and immediately after enriched with chitosan from crab shells (Sigma-Aldrich Ireland Ltd., Dublin Ireland) with a $75 \%$ degree of deacetylation. The juices were enriched with chitosan at concentrations between 0 and $2 \mathrm{~g} \mathrm{~L}-1(\mathrm{w} / \mathrm{v})$. The juice was stored at $4{ }^{\circ} \mathrm{C}$ in sterilised and opaque polyethylene containers $(25 \mathrm{~cm} \times 12 \mathrm{~cm} \times 12 \mathrm{~cm}$ with a 50-mm thickness and 1-L capacity). Conventionally treated (pasteurised) juice was enriched with the optimum chitosan concentration for its use as a reference in sensorial and structural analysis. Samples were pasteurised at $98^{\circ} \mathrm{C}$ for $15 \mathrm{~min}$. Afterward, the orange juice was immediately cooled in ice water for $2 \mathrm{~min}$. The juices were stored in refrigeration and darkness at $4{ }^{\circ} \mathrm{C}\left( \pm 1^{\circ} \mathrm{C}\right)$ without controlled humidity. Samples were analysed by triplicate immediately after processing.

\subsection{Quality parameters}

\subsection{1. $\mathrm{pH}$ measurement}

$\mathrm{pH}$ of $20 \mathrm{~mL}$ samples were determined at room temperature and constant agitation using a pH-meter (model 420A, Orion, USA). It was expressed as the negative logarithm of the hydrogen ion concentration in a solution.

\subsubsection{Total soluble solids ${ }^{\circ}($ Brix $)$}

The Brix was determined by measurement of the refraction index with a refractometer (Bellingham and Stanley, England) at $20^{\circ} \mathrm{C}$. Refractive index was recorded and expressed as ${ }^{\circ}$ Brix. Measurements were performed at $20^{\circ} \mathrm{C}$.

\subsubsection{Colour measurement}

CIEL *a*b* colour parameters were measured in a Minolta colorimeter (Minolta, Model CM-3600d, United Kingdom) controlled by a computer that calculated colour from the reflectance spectrum. Samples were placed in petri dishes and filled to the top. The petri dish was placed directly on the colorimeter sensor $(3.5 \mathrm{~cm}$ in diameter) and measured; three measurements were taken per treatment per day. The instrument was calibrated using a white tile $\left(L^{*}=93.97\right.$, $a^{*}=-0.88$ and $b^{*}=1.21$ ) as standard. The $L^{*}$ parameter (lightness index scale) ranges from 0 (black) to 100 (white). The a parameter indicates the degree of red $(+a)$ or green $\left(-a^{*}\right)$ colour and the $b^{*}$ parameter measures the degree of yellow $(+b)$ or blue $\left(-b^{*}\right)$ colour. The CIELa* $b^{*}$ parameters were converted to Hue $\left(\arctan b^{*} / a^{*}\right)$, Chroma $\left(a^{2}+b^{2}\right)^{\circ}$. The results were expressed in accordance with the CIELAB system with reference to illuminant D65 and with a visual angle of $10^{\circ}$

\section{Materials and methods}

\subsection{Sample collection}

Spanish oranges (Citrus sinensis (L.) Osbeck) of the cv. Navelina and cv. Valencia late were purchased at a local supermarket (Dunnes Stores, North Earl Street, Dublin. Ireland) stored unwrapped and in bulk. Oranges with less than $75 \mathrm{~mm}$ or more than $90 \mathrm{~mm}$ of diameter were discarded. The oranges were brought to the laboratory and stored at $4{ }^{\circ} \mathrm{C}$ until processing.

\subsection{Orange juice}

Unpeeled oranges were manually washed with tap water, cut in halves and squeezed using an automatic juicer (model MPZ-9, Braunn, Germany) on the same day of purchase (Fig. 1); the juice was produced in a food processing laboratory at $18-20^{\circ} \mathrm{C}$. Freshly

\subsubsection{Potential browning}

Potential browning was measured according to the methodology of Viňa and Chaves (2006). Ten milliliters of fresh orange juice was treated with ethanol for $60 \mathrm{~min}$ and then centrifuged at $4830 \times \mathrm{g}$ at $10^{\circ} \mathrm{C}$ for $10 \mathrm{~min}$, retaining the supernatants. After a further amount of ethanol was added to bring the final volume to $25 \mathrm{~mL}$. Absorbance at $320 \mathrm{~nm}$ of aliquots of these extracts was measured. The results were expressed as absorbance units (AU) $\mathrm{mL}-1$ fresh orange juice.

\subsubsection{Turbidity}

The turbidity of each sample of juice was measured using a direct reading spectrophotometer (model DR/2000, Hach, USA). The wavelength of the instrument was brought to $810 \mathrm{~nm}$ and deionised water used as a blank. The measurements of the samples of orange juice were done in triplicate with a solution of 1:25 (juice/water), to work with in the detectable range. The results were given in milligrams of suspended solids per litre of solution. 


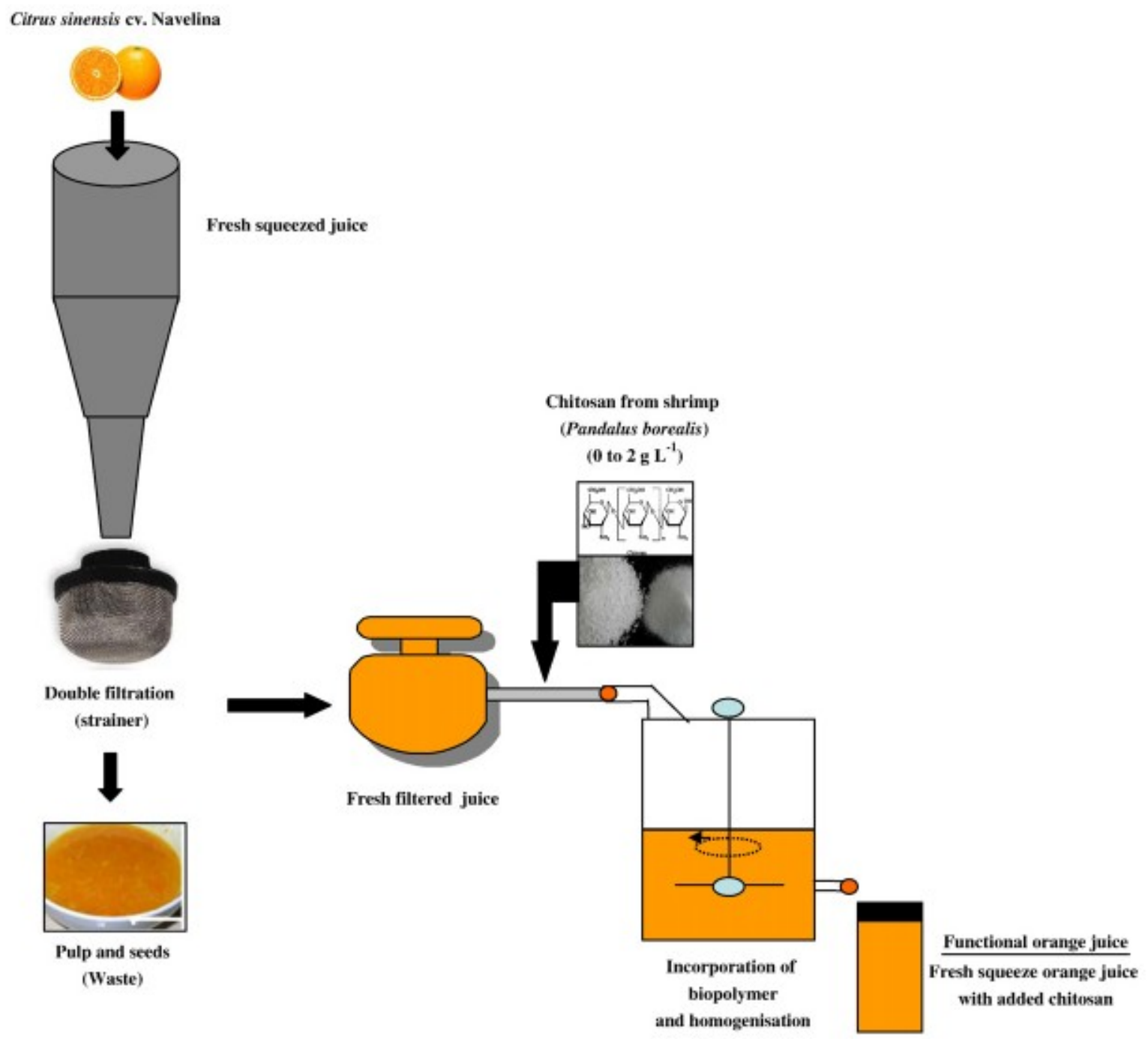

Fig. 1. Juice processing chart.

\subsubsection{Viscosity}

Viscosity of each sample of orange juice was measured using a Brookfield viscosimeter model RVT (Brookfield Engineering Laboratories Inc, USA). Spindle number one was used and the speed was set to $50 \mathrm{rpm}$ for $1 \mathrm{~min}$ in $180 \mathrm{~mL}$ of sample. Only the 10th round readings were recorded ( $\mathrm{Pa} \mathrm{s})$

\subsubsection{Rheology}

Rheological measurements were carried out using a Rheometer (Haake Rheostress 1, Thermo Electron Corporation, Germany) coaxial cylinder sensor system. It was fitted with the Z34DIN (serie 1) measuring head and the Z34DIN (serie 1) rotor system. Experiments were applied across a range of shear stress rates from 0 to $150 \mathrm{~s}-1$ within $180 \mathrm{~s}$. Thermostatic bath (Haake Phoenix C25P, Thermo Electron Corporation, Germany) containing water was used to control the working temperature within the range of $4-71.7^{\circ} \mathrm{C}$. The instrument was linked to a computer for control and constant data collection ( $\mathrm{Pa}$ s)

\subsubsection{Cryo scanning electron microscopy (Cryo-SEM)}

Cryo-SEM was used to observe the effects of chitosan on fresh orange juice. Samples were taken with a Pasteur pipette and a drop was left on a rivet, on the microscope slide. After that, another rivet was put up-side down on the drop. Thus, by capillary action the drop rose up along the rivet to obtain a flat fracture. The samples were frozen by immersion in Slush Nitrogen $\left(-210^{\circ} \mathrm{C}\right)$. After that, the samples were fractured at $-94.5 \circ \mathrm{C}, 10-5$ Torr vacuum, for $15 \mathrm{~min}$, gold coated and viewed in the cold-stage scanning electron microscope (JEOL JSM-5410). Using this technique, the fractured surface of the frozen sample was viewed directly while being maintained at $-150^{\circ} \mathrm{C}$ or lower (Bomben \& King, 1982). Micrographs at day 1 (after treatment) and after 10 days of storage at $4{ }^{\circ} \mathrm{C}$ were analysed. Two different magnifications were analysed $(\times 350$ and $\times 1000)$. Two samples per treatment were used and $\sim 10$ micrographs per sample were obtained.

2.3.9. Pectin methylesterase determination (PME)

PME activity was measured using a modified method described by Kimball (1991). Ten milliliters of orange juice was mixed up with $20 \mathrm{~mL}$ of extraction solution at the temperature of $4{ }^{\circ} \mathrm{C}$. The homogenate was centrifuged (model 2K15, Sigma, Germany) at 12,100 $\times g$ and $4{ }^{\circ} \mathrm{C}$ for $30 \mathrm{~min}$. The supernatant was filtered through a Whatman No. 4 filter paper and the volume obtained was measured. Six milliliters of supernatant was added to $40 \mathrm{~mL}$ of the substrate solution and the system was brought to $\mathrm{pH} 7$ with $0.5 \mathrm{~N} \mathrm{NaOH}$. After the $\mathrm{pH}$ reached $7.5 ; 0.2 \mathrm{~mL}$ of $0.05 \mathrm{~N} \mathrm{NaOH}$ was added. The time required to return to $\mathrm{pH} 7.5$ was recorded. Activity was quantified as carboxyl groups formed by the hydrolysis of methyl esters of pectin and 
was measured tritrimetrically using a $\mathrm{pH}$ electrode to monitor the production:

$$
P E U=\frac{(0.05 \mathrm{~N} \mathrm{NaOH}) *(0.1 \mathrm{ml} \mathrm{NaOH})^{*} 10^{3} *(\text { Vextractml })}{\left.(\text { Vsample })^{\star}(\mathrm{t} \mathrm{min})\right)^{\star 0.5}}
$$

\subsubsection{Aerobic counts}

Microbiology analyses were carried out on the samples at regular intervals through the storage period. One milliliter of decimal dilution of orange juice samples was pipetted to petri dishes $(25 \mathrm{~mL}$ of fresh orange juice was homogenised in $225 \mathrm{~mL}$ of $0.1 \%$ (w/v) sterile peptone water with a Stomacher circulator homogeniser). An enumeration of total counts was carried out at $30^{\circ} \mathrm{C}$ on plate count agar (PCA) over $72 \mathrm{~h}$. The results were expressed as log 10 colony forming units per $\mathrm{kg}$ (CFU $\mathrm{mL}-1)$.

\subsubsection{Sensory analysis}

Analytical descriptive tests were used to discriminate between the sensory quality attributes of fresh orange juice. The panel, which consisted of 15 judges aged 19-35 years (all members of the University Polytechnic of Valencia) with sensory evaluation experience, was trained in discriminate evaluation of fresh orange juice. Panelists were required to score changes in fresh appearance, texture, general acceptability, taste and flavours. Before the start of the sensory experiments, panel members were familiarised with the product and scoring methods. This consisted of demonstration exercises involving examination of orange juices at different levels of deterioration and agreeing appropriate scores. When the panel members had become familiar with the test facilities and scoring regime, they were invited to score samples. This procedure was repeated several times until a level of consistency in scoring was obtained. The same bottle of juice was scored during the entire trial for sensory analysis (10 days). During this training, the samples were presented to the panel to evaluate and measure the reproducibility of the judges' answer and their capability in discriminating among samples. During the analyses, samples were presented in randomized order to minimize possible sequence influence. Two sensory analysis trials were carried out in parallel. The first analysis consisted of each panelist evaluating 16 samples, according with RSM design (Table 1). The second analysis involved four different samples: fresh orange juice, fresh orange juice pasteurised and the fresh juice enriched with the optimum chitosan concentration (1 g L-1) (according to the results generated for the polynomial model for the quality and nutritional markers) at regular intervals during storage time ( 1 and 10 ).

For both analysis the samples were evaluated using a five point numerical rating scale for: (I) General acceptability, where $0=$ not acceptable, $2.5=$ acceptable and $5=$ high acceptability; (II) Texture, where $0=$ bad texture, $2.5=$ moderate and $5=$ very good texture; (III) Flavour, where $0=$ very bad, $2.5=$ moderate and $5=$ very good and (IV) Off-odour, where $0=$ very bad/fresh, 2.5 = moderate, and $5=$ very bad. Sensory evaluation was used to determine the shelf-life of the functional juices and scores equal to or below 2.5 were taken as unacceptable. Data analysis was collected using Compusense ${ }_{\circledast}$ Five software (Release 4.4, Ontario, Canada).
2.4. Nutritional parameters

\subsubsection{Ascorbic acid}

The 2,6-dichlorophenolindophenol (DCPIP) solution was titrated to find the indophenol factor, which is necessary to standardise the experiment. Three samples of $2 \mathrm{~mL}$ each of standard ascorbic acid solution were introduced into Erlenmeyer flasks with $5 \mathrm{~mL}$ of the extraction solution ( $3 \% \mathrm{w} / \mathrm{v}$ of meta-phosphoric acid dissolved in a $8 \%$ glacial acetic acid) The end point of DCPIP addition was determined when a pink colour was achieved. The titrations did not differ by more than $1 \mathrm{~mL}$. Three blank titrations were done, using $7 \mathrm{~mL}$ of acetic metaphosphoric acid and the amount of water equivalent to the amount of DCPIP used in the direct appraisal. Finally, the average of both tests was subtracted and result was expressed in $\mathrm{mg}$ of ascorbic acid equivalent to $1 \mathrm{~mL}$ of the DCPIP solution. To calculate the indophenol factor, the $2 \mathrm{mg}$ of ascorbic acid was used. To determinate the amount of ascorbic acid in the different orange juices, $10 \mathrm{~mL}$ of sample was placed in a volumetric flask and, it was brought to $100 \mathrm{~mL}$ with the extraction solution. This was done in triplicate. The blank was measured, with two samples of $10 \mathrm{~mL}$ of extraction solution that were titrated with the DCPIP solution. The results were expressed in $\mathrm{mg}$ of ascorbic acid per $\mathrm{mL}-1$ of sample, and it was calculated with the following equation:

$\mathrm{mg}$ of ascorbic acid $\mathrm{mL}^{-1}$ of sample $=(X-B)^{*}(F / E)^{*}(V / Y)$

where $X=$ average of the volume of indophenol solution used in the titration of the sample, $B=$ average of the volume of indophenol solution used in the titration of the blank, $\mathrm{F}=$ indophenol factor, $E=m L$ of sample used $(10 \mathrm{~mL}), V=$ final volume of the extraction of the sample $(100 \mathrm{~mL}), \mathrm{Y}=$ aliquot of $\mathrm{V}$ which has been titrated $(10 \mathrm{~mL})$.

\subsubsection{Carotenoids}

The measurement of the total carotenoids was based on the Cyanotech Corporation method (Cyanotech Corporation, 2001) with slight modifications, according to Alasalvar, Al-Farsi, Quantick, Shahidi, and Wiktorowicz (2005). Orange juice samples of $0.5 \mathrm{~mL}$ were in $25 \mathrm{~mL}$ of acetone containing dimethyl sulphoxide (10\% in ice bath). All manipulations were carried out without direct lighting, because carotenoids are very sensitive to light, heat and air. The homogenate was filtered through a Whatman No. 4 filter paper. Finally, it was washed and brought to $100 \mathrm{~mL}$ with the same acetone and dimethyl sulphoxide solution and the absorbances at $471 \mathrm{~nm}$ were measured against an extraction solvent blank, in triplicate for each juice sample, using a spectrophotometer (spectronic 1201, Milton Roy, USA). Total carotenoids were calculated according to the following equation:

\section{$\mathrm{mg}$ of carotenoids $\mathrm{mL}^{-1}$ of sample \\ $=$ Absmax $/ 250^{\star} 100 \mathrm{ml}$ ace tone dilution $/$ sample volume $(\mathrm{mL})$}

\subsection{Experimental design}

The experiments consisted of five independent batches that were carried out between September 2006 and June 2007. Each batch involved the processing of 30-40 kg oranges which were squeezed

Table 1

Ranges for the independent variables (mirimum and maximum).

\begin{tabular}{|c|c|c|c|c|c|c|}
\hline \multirow[t]{2}{*}{ Fuctors } & \multirow[t]{2}{*}{ Code tactars } & \multicolumn{5}{|c|}{ Coded and uncoded values of the experience factars } \\
\hline & & -1.41 & -1 & 0 & +1 & +1.41 \\
\hline Chitosan cancentration $\left(\mathrm{mg} \mathrm{L}^{-}\right)^{-1}$ & FA & 0 & 03 & 1 & 1.7 & 2 \\
\hline Starage fime (days) & $\mathrm{FB}$ & 0 & 1.4 & 5 & 85 & 10 \\
\hline
\end{tabular}

Coded and actual values used for optimisation 
following the methodology described in Fig. 1, obtaining $\sim 1-20 \mathrm{~L}$ of fresh orange juice. The storage time at $4{ }^{\circ} \mathrm{C}$, estimated to be within the shelf-life range of the produce (Fellers, 1988), was set to 10 days after processing. The maximum concentration of chitosan was established as $2 \mathrm{~g} \mathrm{~L}-1$ after an initial sensorial acceptance screening.

The experimental design was based on a central composite design (CCD) (Cochran \& Cox, 1957). The design consisted of a total of 16 running factorial points. The model was designed to study the effect of two independent variables (factor A (FA): chitosan concentration and factor $B$ (FB): storage time) on different quality and nutritional markers (dependent variables) (Table 1). These dependent variables were expressed individually in a function known as the response function of the independent variables. The variance for each factor assessed was delineated linear, quadratic and interactive components and expressed using a second-order polynomial function. The threedimensional plots (surface plots) of the fitted polynomial were generated to visualise the relationships between the responses and the independent variables using the statistical software.

\subsection{Statistical analysis}

RSM was used to fit the experimental data to the quadratic polynomial equation to obtain coefficients of the equations. The model and statistical analyses and contour plots were analysed using Statgraphics software 2.1 (Statistical Graphics Co., Rockville, USA). For comparison of chitosan at optimum concentration with fresh juice in sensory analysis trials ANOVA (Multifactor and one-way) was performed to examine differences between treatment, storage time and interaction of both factors with each one of the variables studied.

Means were compared by significant difference (LSD) test, at a significance level $p=0.05$ using the Statgraphics software (version 2.1; Statistical Graphics Co., Rockville, USA).

\section{Results and discussion}

\section{1. $\mathrm{pH}$ measurement}

The $\mathrm{pH}$ was significantly ( $\mathrm{p} \mathrm{b}$ 0.05) affected by chitosan concentration (FA) and storage time (FB). The polynomial model explained $93 \%$ of $\mathrm{pH}$ data variation with these two factors (Fig. 2). The $\mathrm{pH}$ increased significantly ( $p$ b 0.05) with increasing chitosan concentration, and both linear and quadratic effects were observed. This resulted in relatively high $\mathrm{pH}$ range values (4.1-5.7) can be observed in Fig. 2, compared with previous studies (Kelebek, Canbas, \& Selli, 2008) in fresh orange juice, who found $\mathrm{pH}$ values between 3.05 and 3.35 in $\mathrm{C}$. sinensis (variant Sanguinello and Moro). The $\mathrm{pH}$ values were also higher than those observed by Martin-Diana et al. observed in the laboratory by MartinDiana et al. in juices enriched with chitin, which ranged between 3.2 and 4.2. This effect could be due to the capacity of chitosan to reduce

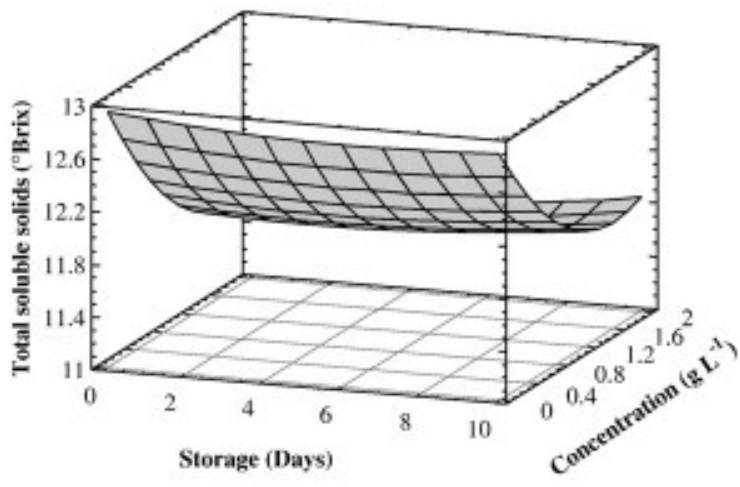

Fig. 3. Response surface methodology for total soluble solids ( ${ }^{\circ}$ Brix) as a function of chitosan concentration ( $\mathrm{g} \mathrm{L}-1)$ and storage time (days) in fresh orange juice packaged and stored at $4{ }^{\circ} \mathrm{C}$.

fruit juice acidity (Imeri \& Knorr, 1988) based on its acid-binding properties. When the $\mathrm{pH}$ is lower than 6.5 , chitosan carries a positive charge along its backbone (Einbu \& Varum, 2003). This also might imply a decrease in the buffering property of the juice, but such effect was not observed in this study, as all the samples showed a similar $\mathrm{pH}$ increase over storage time and no interaction effect resulted from storage time and chitosan concentration. Also the $\mathrm{pH}$ increase the juices undergo over storage time has been associated to microbial spoilage (Del Caro, Piga, Vacca, \& Agabbio, 2004; Cortés et al., 2008).

\subsection{Total soluble solids (Brix)}

The polynomial model explained $90 \%\left(R_{2}\right)$ of the variability in total soluble solids due to the effect of the concentration. A linear and quadratic effect was observed on the concentration meanwhile no significant effect of storage time was observed (Fig. 3). Chitosan reduced the $\mathrm{Brix}^{\circ}$ value of the orange juices (linear and quadratic effects). No significant changes over storage time were observed. This is in agreement with other authors (Ayhan et al., 2001; Bull et al., 2004; Rivas et al., 2006; Cortés et al., 2008). The ${ }^{\circ}$ Brix values in fresh orange juice were higher $\left(12\right.$ to $13.2^{\circ}$ ) compared to those found by other authors (Cortés et al., 2008) in untreated fresh orange juice $\left(11.8 \pm 0.1^{\circ}\right)$ and also higher than those found in previous studies by the authors in juices enriched with chitin $\left(9.8\right.$ to $\left.11.4^{\circ}\right)$. These differences in the fresh juice without chitosan might be due to different factors, i.e. genetic, growing environment, management practices and maturity time of the fruit (Quadir, Hickey, Boulton, \& Hoogers, 2006). The significant $(p<0.05)$ quadratic reduction of ${ }^{\circ} B r i x$ with the concentration of chitosan could be explained by the ability of the positive charged polysaccharide to coagulate suspended solids, increasing the flocculation capacity of chitosan which could bind the sugar (negatively charged) (Figs. 4 and 5) (Sapers, 1992).

\subsection{Colour measurement}

The variations in CIEL*a*b* colour parameters (luminosity, a , b , hue and chroma) due to chitosan concentration and storage time are shown in Figs. 4 and 5 . The polymeric model explained $41 \%$ of the variability of the luminosity due to the effect of concentration and storage time. A significant $(p<0.05)$ increase in luminosity of the juices was observed with increasing chitosan concentrations. These results could be explained by the clarification effect described in fruit juices associated to chitosan (Soto-Peralta, Muller, \& Knorr, 1989; Chatterjee, Chatterjee, Chatterjee, \& Guha, 2004; Rungsardthong, Wongvuttanakul, Kongpien, \& Chotiwaranon, 2006). Also the increment in whiteness and brightness could be due to the natural colour of the biopolymer, which would produce a blanching effect on the juice; this effect was present especially at higher concentrations (Fig. 4I). 

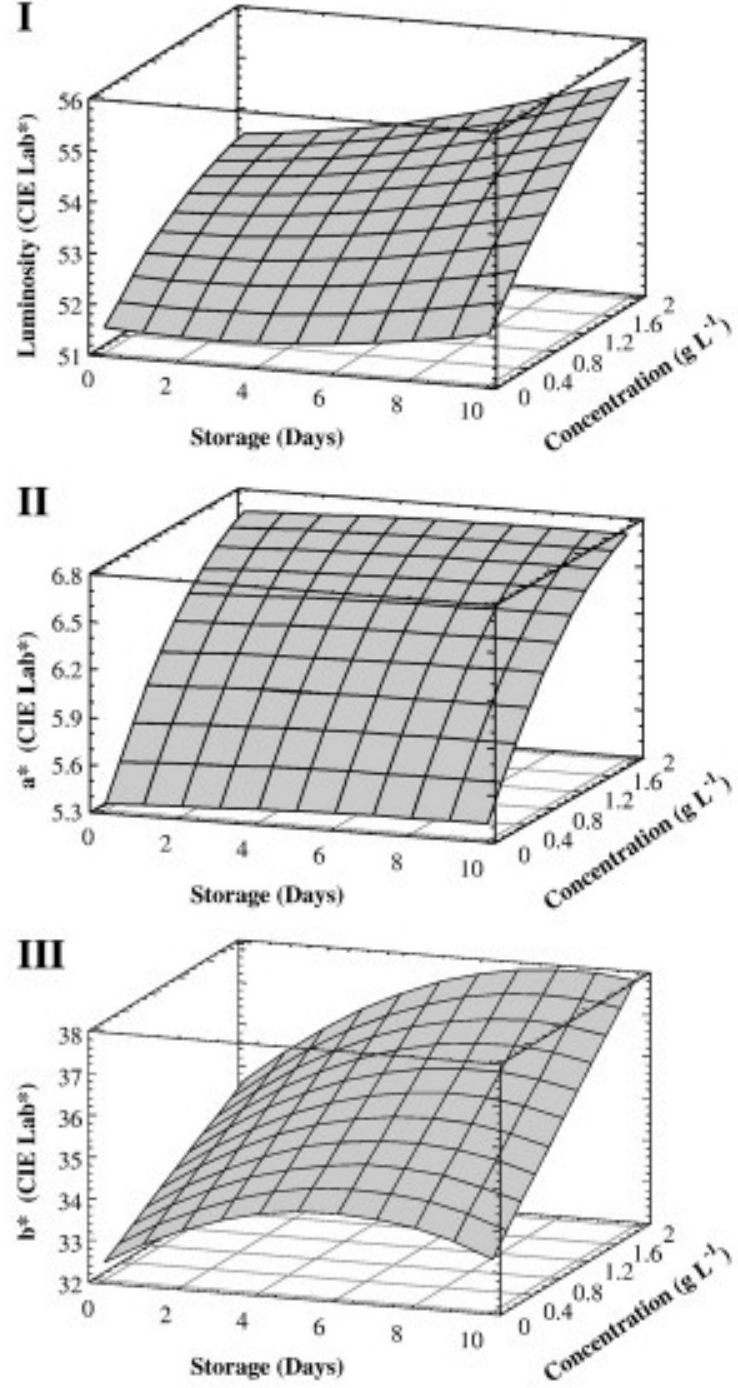

Fig. 4. Response surface methodology for changes in CIE Lab (Luminosity, a and b ) as a function of chitosan concentration $(\mathrm{g} \mathrm{L}-1)$ and storage time (days) in fresh orange uice packaged and stored at $4{ }^{\circ} \mathrm{C}$. Changes in Luminosity (I), changes in a value (II) and changes in b value (III).

The decrease in luminosity during the storage time in fresh orange juices is attributed to the decantation of unstable particles in juice during the storage time (Genovese, Elustondo, \& Lozano, 1997) and pigment break down, mainly carotenoids and lycopene (Shi \& Maguer, 2000; Krebbers et al., 2003; Meléndez-Martínez, Vicario, \& Heredia 2003; Vikram, Ramesh, \& Prapulla, 2005); however, juices treated with chitosan did not show this behaviour (Fig. 4). Chitosan controlled the increase in luminosity up to 6-7 days of storage; after, a significant increase in luminosity was observed. The control of luminosity in the juices could be associated to the ability of the positively charged polymer to coagulate the suspended solids, to which browningrelated enzymes are bounded (polyphenol oxidase, PPO, and Peroxidase, POD), resulting in browning inhibition.

Fig. 4II shows the influence of chitosan concentration and storage time on $a^{*}$ value. A significant increase of a was observed with increasing chitosan concentrations. The model explained $92 \%$ of the variability of $a^{*}$ due to the effect of chitosan concentration and storage time. The initial $a^{*}$ values were higher $(\sim 5.3)$ in juices fortified with chitosan than in juices fortified with chitin. This would indicate a higher orange colour in juices with chitosan. This could be associated with the lower bleaching effect of chitosan compared to chitin. The maximum values in both cases were observed at the end of storage time with no differences between them (6.8 for chitosan and 6.0 for chitin). No significant differences ( $p$ b 0.05) during storage time were observed (Fig. 4II). Since the decrease in a values could be associated with the increase in non-enzymatic and enzymatic browning-related, the incorporation of chitosan had significant control of the degradation of pigments (non-enzymatic browning) and also controlled the browning-related enzymes (PPO and POD).

The $b^{*}$ values were analysed through storage time in juices enriched with different concentrations of chitosan. The model explained $73 \%$ of the changes of the $b^{*}$ value due to the chitosan concentration and storage time. Three-dimensional plots (Fig. 4III) described that increments of chitosan produced significant linear and quadratic effects $(p<0.05)$, showing an increase in yellowness, mainly at higher concentrations. The storage time affected significantly ( $p$ b 0.05) the juice $b^{*}$ value (Fig. 4III). Higher concentrations of chitosan produced juices with higher $b^{*}$ values.

Changes in Hue and Chroma were explained by $86 \%$ and $73 \%$ respectively by the model. The concentration of chitosan produced significant $(p<0.05)$ changes in colour (hue) and a significant positive effect of chitosan concentration was observed on the chroma values. The concentration of chitosan increased the intensity of the colour (Fig. 5). This higher intensity could be associated to the reduction of browning and indirectly to the control of the luminosity. The hue and chroma values were also affected by the storage time. The intensity and brightness of the colour did not decrease, as it would be expected according to previous work in fresh orange juice and juices with incorporated chitin.

\subsection{Browning potential}

According to the model $\left(\mathrm{R}_{2}=50 \%\right)$ the main factor that affected the browning potential (BP) was storage time followed by chitosan concentration (Fig. 6). An interactive effect between chitosan concentration and storage time on the BP was also observed. In samples with lower or no chitosan concentration the BP increased rapidly over
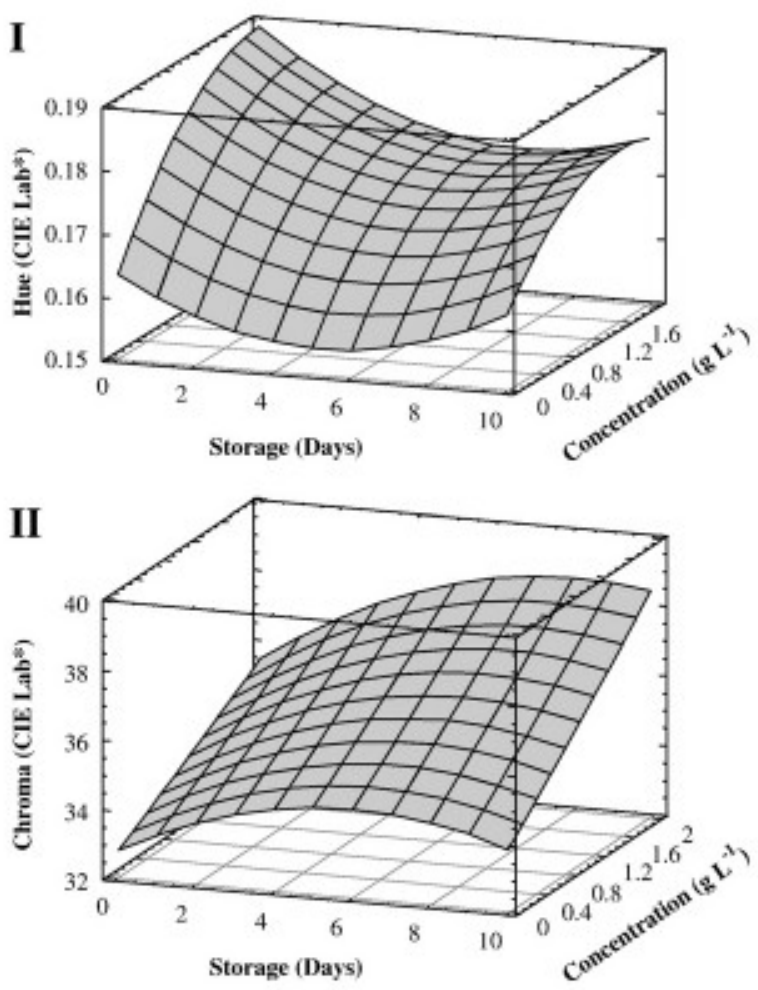

Fig. 5. Response surface methodology for changes in CIE Lab* (chroma and hue) as a function of chitosan concentration $(\mathrm{g} \mathrm{L}-1)$ and storage time (days) in fresh orange juice packaged and stored at $4{ }^{\circ} \mathrm{C}$. Changes in chroma (I) and changes in hue (II). 


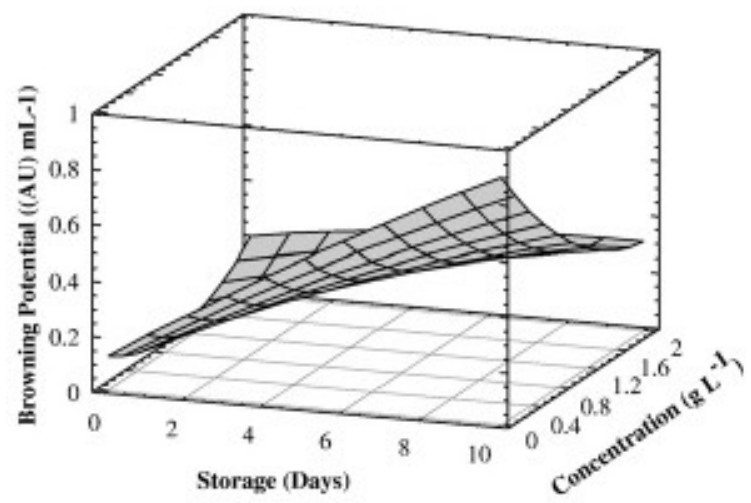

.6. Response surface methodology for changes in potential browning ((AU) $\mathrm{mL}-1)$ as a function of chitosan concentration ( $\mathrm{g}-1$ ) and storage time (days) in fresh orange juice packaged and stored at $4{ }^{\circ} \mathrm{C}$.

storage time, while it remained almost constant in samples with higher chitosan concentration (Fig. 6). Chitosan has been found to enhance the control of enzymatic browning in apple and pear juice (Sapers, 1992). This datum was in accordance with colorimeter measurements which showed a significant relationship between chitosan concentration and inhibition of browning. The control of browning could be associated with the capacity to coagulate solids to which browning-related enzymes are bound. The antioxidant capacity of chitosan, similar to the capacity associated with phenolic compounds (Park, Je, \& Kim, 2004), could also explain this browning reduction by inhibiting the oxidative process.

\subsection{Turbidity}

The polynomial equation explained $89 \%\left(R_{2}\right)$ of the variability of turbidity due to storage time and chitosan concentration. Fig. 7 shows the variation of turbidity at different chitosan concentrations and over storage time; significant ( $p$ b 0.05) linear effects of the storage time and chitosan concentration were observed (Fig. 7). Fresh orange juices are usually cloudy and this is an acceptable and desirable component (Sin, Yusof, Sheikh Abdul Hamid, \& Rahman, 2006). The turbidity in the juice is mainly caused by the polysaccharides present in the juice (Grassin \& Fauquembergue, 1996). Concentration of chitosan controlled the turbidity of the orange juice. These results were in agreement to Chatterjee et al. (2004) who reported a decrease in turbidity due to chitosan addition. The use of chitosan has been studied for juice clarification (Soto-Peralta et al., 1989; Chatterjee et al., 2004; Rungsardthong et al., 2006). The storage time affected significantly ( $p$ b 0.05) the juice turbidity; lower concentrations

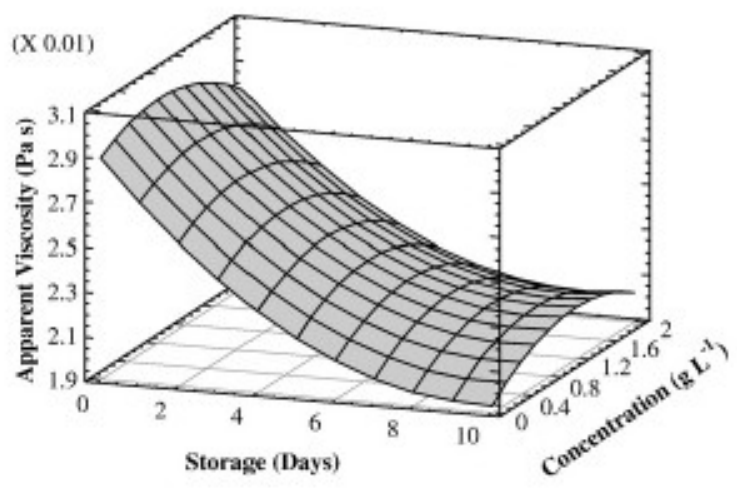

Fig. 8. Response surface methodology for changes in apparent viscosity ( $\mathrm{Pa} \mathrm{s}$ ) as a Fig. 8. Response surface methodology for changes in apparent viscosity (Pa s) as a
function of chitosan concentration ( $\mathrm{L}$ L-1) and storage time (days) in fresh orange juice packaged and stored at $4{ }^{\circ} \mathrm{C}$.

of chitosan produced higher turbidity juices than higher chitosan concentrations.

\subsection{Apparent viscosity}

The model for apparent viscosity fitted results very good $(\mathrm{R} z 90 \%$, resulting in a reliable explanation of the behaviour of viscosity due to chitosan concentration and storage time (Fig. 8)). The

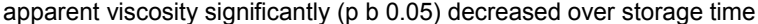
(linear and quadratic effects); this might be due to a degradation of pectin compounds, resulting in a reduction of water holding capacity and free water released to the system (Abdullah, Sulaiman, Aroua, \& Megat Mohd Noor, 2007). The concentration of chitosan did not affect the viscosity of the juices.

The dispersing phase where the main components of juices (sugars, acids, salts, proteins and soluble pectin) are dissolved changed during the storage time significantly ( $p$ b 0.05). The decrease in the apparent viscosity, which might be due to pectin degradation, was similar for higher and low concentrations of chitosan, which indicated no differences in the pseudoplastic or shear-thinning nature of the juice (Khandari, Gill, \& Sodhi, 2002). Authors found differences in the shear-thinning nature of juice with chitin, differences which could be associated to the different solubility of chitosan and chitin The concentration did not affect significantly ( $p$ b 0.05) the viscosity during the storage time, juices with higher chitin concentration had higher viscosities than juices with lower chitin concentrations, which might indicate that the degradation only affected the natural polysaccharides of the orange juice and not external added sources.

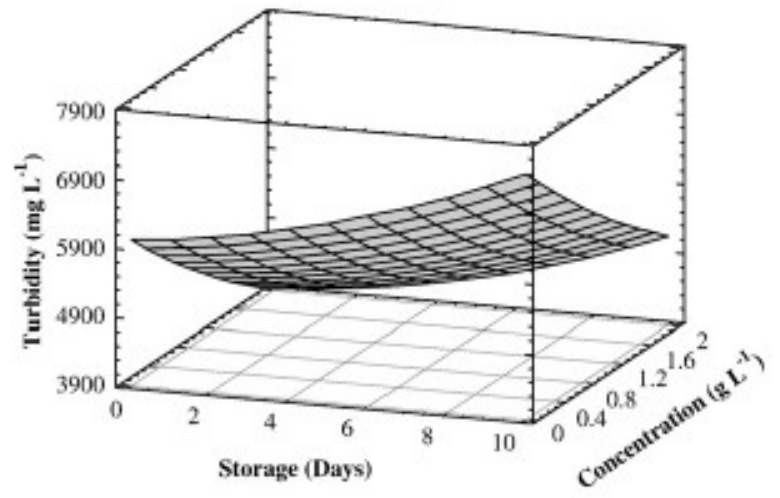

Fig. 7. Response surface methodology for changes in turbidity ((AU) $m g \mathrm{~L}-1)$ as a function of chitosan concentration ( $\mathrm{L} L-1)$ and storage time (days) in fresh orange juice packaged and stored at $4{ }^{\circ} \mathrm{C}$ $\underline{0 \mathrm{LL}^{-1}} \quad 0.5 \mathrm{~g} \mathrm{~L}^{-1} \quad \quad 1 \mathrm{~g} \mathrm{~L}^{-1} \quad 1.5 \mathrm{gL}^{-1} \quad \underline{2.0 \mathrm{gL}^{-1}}$

(X 0,001$)$

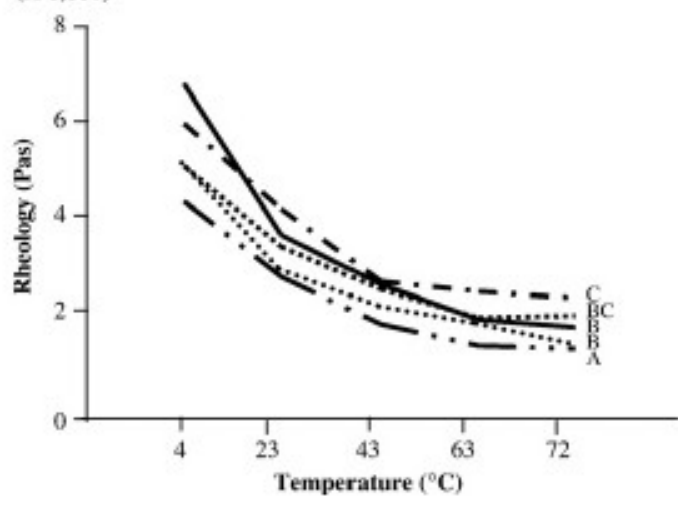

Fig. 9. Changes in rheological viscosity ( $\mathrm{Pa} \mathrm{s}$ ) as a function of chitosan concentration $(\mathrm{g} \mathrm{L}-1)$ and temperature $\left({ }^{\circ} \mathrm{C}\right)$ in fresh orange juice packaged and stored at $4{ }^{\circ} \mathrm{C}$. 


\subsection{Rheology}

The rheological behaviour of the juices, expressing the strain rate in $\mathrm{Pa}$, the first day of storage time measuring at different shear stress rates in the range from 0 to $150 \mathrm{~s}-1$ and at different temperatures, from $4{ }^{\circ} \mathrm{C}$ to $72^{\circ} \mathrm{C}$. The results describe all the juice samples as a Newtonian fluid, with a linear dependence between shear stress and strain rate. Juices with higher concentration showed higher values than juices with lower concentration (Fig. 9). The consistency coefficient showed a positive correlation with inverse absolute temperature and it also increases nonlinearly with increasing concentration. The fitted model explained $83.55 \%$ of the variability of the consistency due to concentration and storage time. The storage time significantly $(p<0.05)$ affected the rheological properties of the juices. A decrease during the storage time was observed regardless of the chitosan concentration. This could be explained with the increase in the serum phase of the juices as a result of the reduction in water retention as pectin degrades.

3.8. Cryo scanning electron microscopy (Cryo-SEM)

The microstructure of the juice suspension revealed by cryo-SEM (Fig. 10) was a three-dimensional non-oriented network. The pore spaces were around 1-2 $\mu \mathrm{m}$ in diameter in juices enriched with chitosan, and larger in juices with low chitosan concentration or without chitosan (Fig. 10I and II). It would seem to be the result of the breaking of the bridges between particles as can be seen at the highest magnification. Higher concentrations of chitosan could have reduced the liquid phase crystal size causing an increase of total external surface of the solids. Cryo-SEM was evaluated in samples before and
I

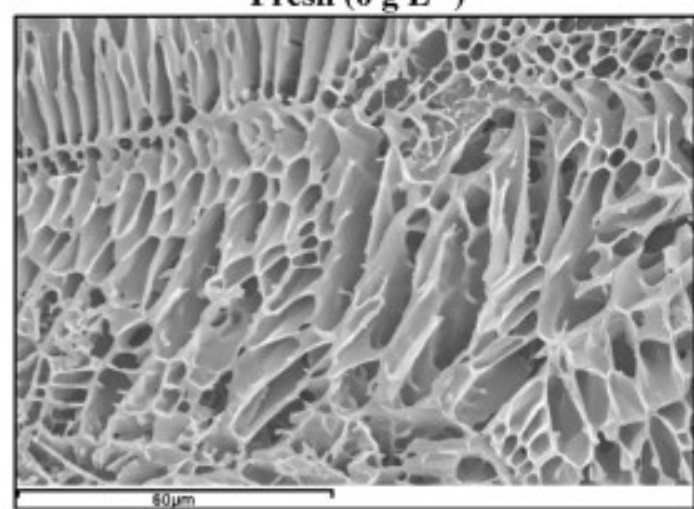

III

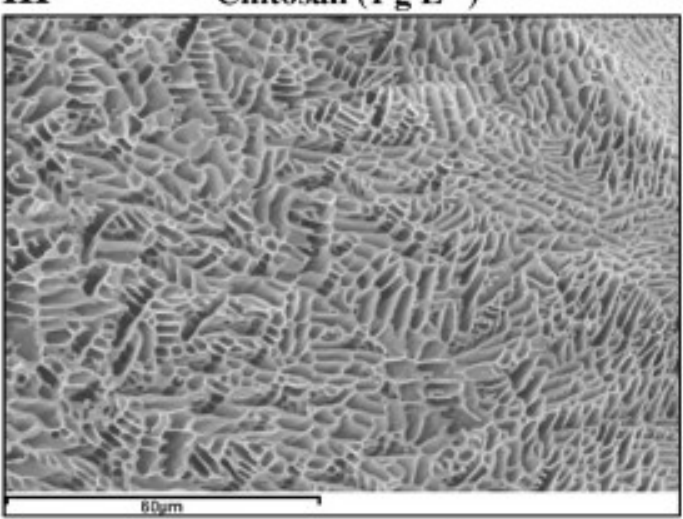

V Chitosan $\left(1 \mathrm{~g} \mathrm{~L}^{-1}\right)$

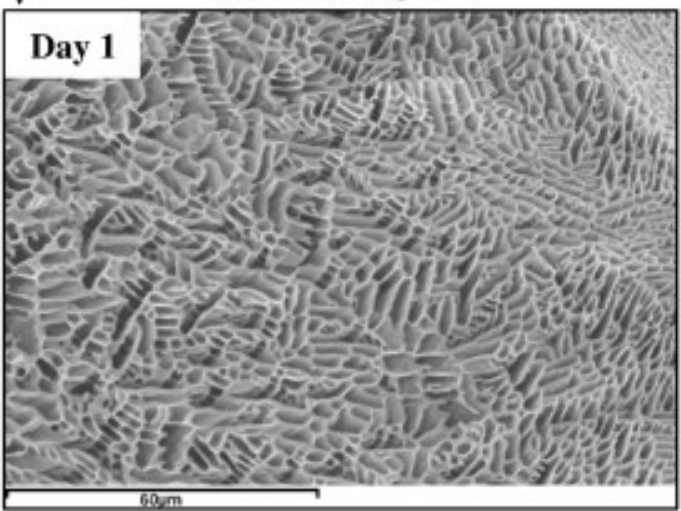

II

Chitosan $\left(1 \mathrm{~g} \mathrm{~L}^{-1}\right)$

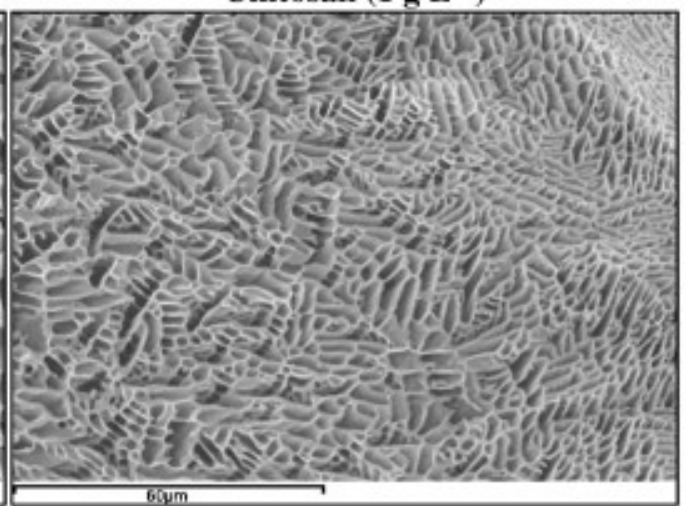

IV Pasteurised Chitosan $\left(1 \mathrm{~g} \mathrm{~L}^{-1}\right)$

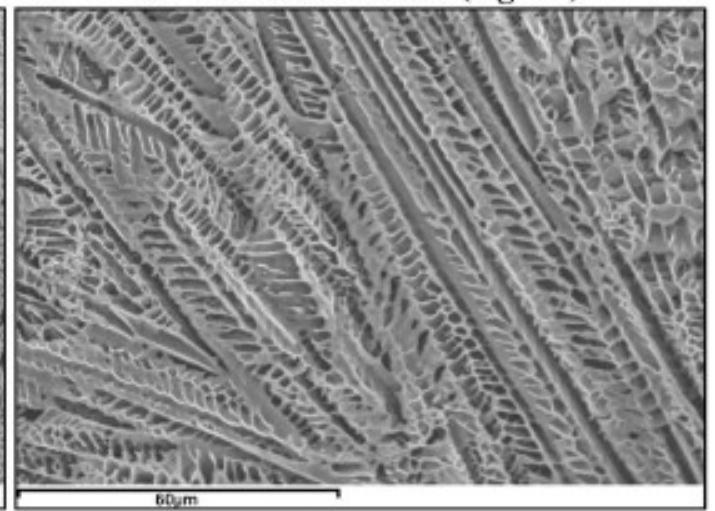

VI Chitosan $\left(1 \mathrm{~g} \mathrm{~L}^{-1}\right)$

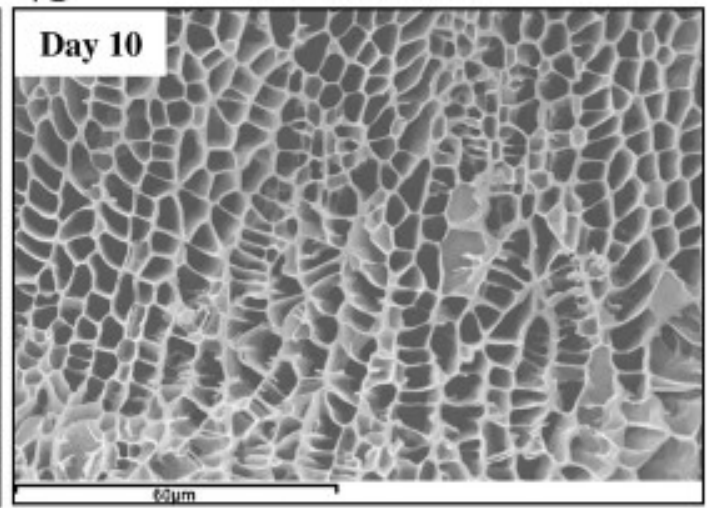

Fig. 10. Cryo-SEM micrographs of fresh orange juice (I), orange juice fortified with $1 \mathrm{~g} \mathrm{~L}-1$ of chitosan (II) stored at $4{ }^{\circ} \mathrm{C}$. Cryo-SEM micrographs of fresh orange juice fortified with $1 \mathrm{~g} \mathrm{~L}-1$ of chitosan (III) and fresh orange juice fortified with $1 \mathrm{~g} \mathrm{~L}-1$ of chitosan and pasteurised (IV) at day 1 . Cryo-SEM micrographs of fresh orange juice fortified with with $1 \mathrm{~g} \mathrm{~L}-1$ of chitosan (III) and fresh orange juice
$1 \mathrm{~g} \mathrm{~L}-1$ of chitosan at day $1(\mathrm{~V})$ and at day $10(\mathrm{VI})$. 
after pasteurisation. Cryo-SEM micrographs showed that the thermal process made the liquid phase crystallise in to smaller crystals (Fig. 10III and IV). Although a similar isotropic network has been observed in juices pasteurised, a major degradation of the network was observed. This phenomenon might represent chitin degradation during the thermal treatment, decreasing the size of the network and causing the increase of the total external surface. Fig. 10V and VI shows the changes in microstructure of the juice enriched with $1 \mathrm{~g} \mathrm{~L}-1$ chitosan over storage. It was observed that the liquid phase crystallisation was in bigger crystals by the tenth day.

\subsection{Pectin methylesterase determination (PME)}

Fig. 11 shows the PME activity behaviour in relation to chitosan concentration and storage time based on the obtained model. The high value of adjusted $R_{2}(89 \%)$ indicated the goodness of fit of the model to the observed data.

In order to retain cloudiness of the juices, low PME activity is desired (Rodrigo, Barbosa-Canovas, Martínez, Rodrigo, 2003b). PME activity increased over storage time, which had significant ( $p$ b 0.05) linear and quadratic effects, with a peak of activity at day 7 . Chitosan also had a significant effect, although in a lower degree than the storage time, increasing the activity of this enzyme. This could be explained by a protein stabilisation effect caused by chitosan, as it has been described with other polymers (Kilinç, Onal, \& Telefoncu, 2002).

This is thought to be due to the interaction of the polyhydroxyl compound with water, favouring protein hydrophobic interactions. The effect of clarification on juices by chitosan (Soto-Peralta et al., 1989; Chatterjee et al., 2004) has been previously described and explained by its coagulating properties. From these results the clarification mechanism could complement the observed effect of PME stabilisation.

\subsection{Aerobic counts}

Fig. 12 shows a significant increase (linear and quadratic effects) of aerobic counts over storage time up to day 7 , with a partial reduction from days 7 to 10 (Fig. 14). Chitosan concentration also significantly affected the aerobic counts of orange juice (linear and quadratic effects), resulting in a positive effect for the extension of the shelf-life. Chitosan (up to $1 \mathrm{~g} \mathrm{~L}-1$ ) reduced (linear and quadratic effects) aerobic counts by $1 \mathrm{log}$, with no further reductions using concentrations from 1 up to $2 \mathrm{~g} \mathrm{L-1}$ (Fig. 14). The differences in aerobic counts between samples with little or no chitosan and those with over $1 \mathrm{~g} \mathrm{~L}-1$ chitosan were maintained over storage time, suggesting an active antimicrobial effect of chitosan occurring over storage time. The antimicrobial application of chitosan has received considerable attention (Yalpani, Johnson, \& Robinson, 1992), with only few attempts on juices investigated (Roller \& Covill, 1999; Kisko, Sharp, \& Roller, 2005; No,

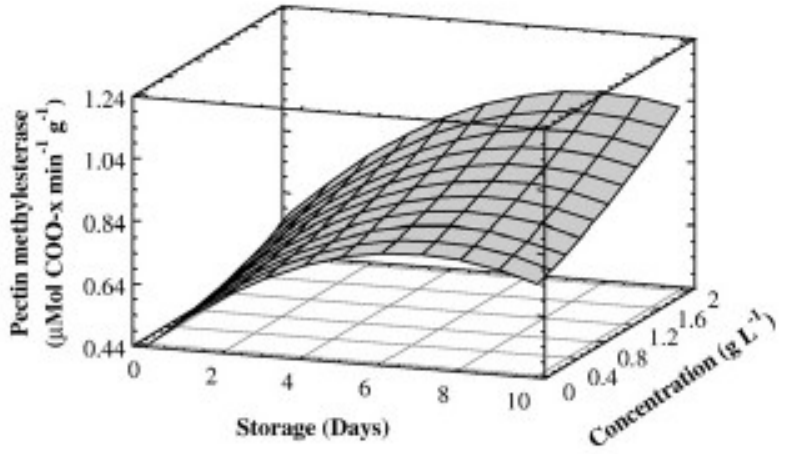

Fig. 11. Response surface methodology for changes in pectinmethyl esterase ( $\mu \mathrm{Mol}$ COO- min- $1 \mathrm{~g}-1)$ as a function of chitosan concentration $(\mathrm{g} \mathrm{L}-1)$ and storage time (days) in fresh orange juice packaged and stored at $4{ }^{\circ} \mathrm{C}$.

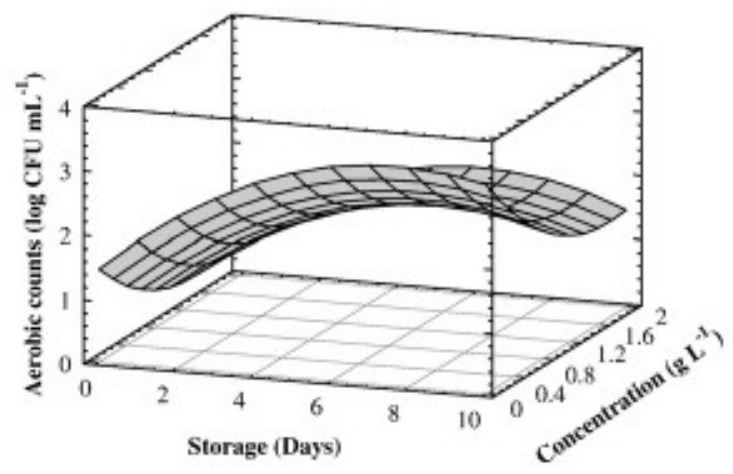

Fig. 12. Response surface methodology for changes in sensory evaluation (general acceptability (I) and flavour (II)) as a function of chitosan concentration (g L-1) and storage time (days) in fresh orange juice packaged and stored at $4{ }^{\circ} \mathrm{C}$.

Meyers, Prinyawiwatkul, \& Xu, 2007). Chitosan's antimicrobial properties have been reported widely in the literature but mainly based on the in vitro trials, and not directly in foods, which are a mixture of different compounds which may interact with chitosan and lead to a decreased or enhanced antibacterial activity (Devlieghere, Vermeulen, \& Debevere, 2004; No et al., 2007). Although the mechanism of chitosan antimicrobial activity is still unknown, several have been proposed (Shahidi, Arachchi, \& Jeon, 1999), for example an increase in the bacterial membrane permeability at mild acidic conditions (Helander, Nurmiaho-Lassila, Ahvenainen, Rhoades, \& Roller, 2001), or the formation of a polymer membrane, preventing nutrients from entering the cell (Zheng \& Zhu, 2003). Suggestions have been made, based on the effect of chitosan on bacterial membrane permeability, of the possibility of applying the hurdle concept in the use of chitosan. The positive reductions observed in this study suggest that possibility could also be applied to the orange juice.

\subsection{Sensory}

Fig. 13 shows the sensory analysis results for the optimisation part of the study. A significant reduction in general acceptability (linear effect) in samples with increasing chitosan concentrations was observed. Chitosan has the ability of reducing the acidity of the juices (Imeri \& Knorr, 1988), but this effect was not reflected in the improvement in the organoleptic properties. This positive effect on the sensory attribute, might have been counterbalanced by an increase in bitterness due to the chitosan (Han, Lederer, McDaniel, \& Zhao, 2005), which could also explain the quadratic effect of chitosan concentration, with a maximum flavour score when low chitosan concentration was used. Fig. $14 \mathrm{I}$ and II shows the differences between juices enriched at optimum concentration ( $1 \mathrm{~g} \mathrm{~L}-1)$, fresh orange

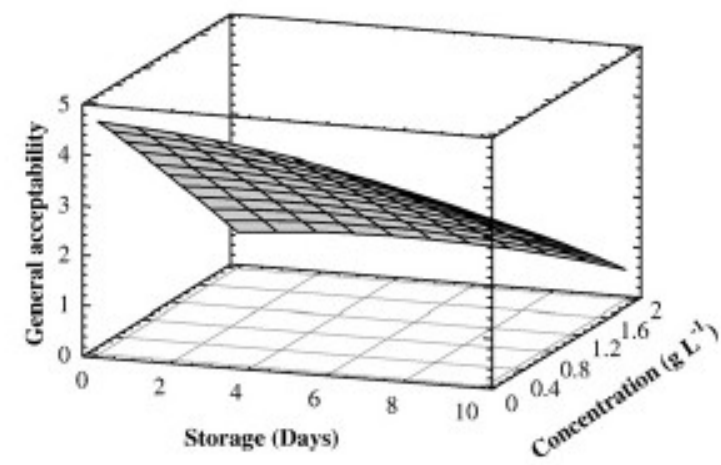

Fig. 13. Changes in sensory evaluation (general acceptability) in fresh orange juice, fresh orange juice pasteurised, fresh orange juice fortified with $1 \mathrm{~g} \mathrm{~L}-1$, and fresh orange juice fortified with $1 \mathrm{~g} \mathrm{~L}-1$ and pasteurised during 10 days of storage. 
juice (no chitosan added) and pasteurised orange juice. Juices enriched with chitosan were considered acceptable (Fig. 14I) at the end of storage, although the initial values were slightly lower than those of fresh orange juice. The panelists considered acceptable the flavour of the juices enriched with chitosan; however, the pasteurisation affected negatively the flavour of juices (Fig. 14II).

\subsection{Ascorbic acid}

The polynomial model explained $71 \%$ of the variability of ascorbic acid due to storage time and concentration of chitosan. Model predicted data is showed in the three-dimensional Fig. 15I, where a significant $(p<0.05)$ linear effect of the storage time and chitosan concentration was observed. Ascorbic acid (AA) content has been described as an indicator of quality in juices and orange juice is consider one of the best sources of vitamin $C$ by the consumers (Shaw \& Moshonas, 1991). All the samples after the 10 days of storage retained the minimal recommended values of ascorbic acid for orange juice $(0.4 \mathrm{mg} \mathrm{mL}-1)$ (Rodrigo et al., 2003a,b). The initial (storage time 0 ) values of ascorbic acid ranged from 0.53 to $0.57 \mathrm{mg} \mathrm{mL}-1$. Storage time and chitosan concentration significantly (linearly) reduced AA content (Fig. 15I). This effect of acid sequestration described for chitosan (Imeri \& Knorr, 1988) might have caused this ascorbic acid reduction. Low chitosan concentrations $(0-0.8 \mathrm{~g} \mathrm{~L}-1)$ did not affect the AA content, which decreased in samples with higher chitosan concentration (quadratic effect).

\subsection{Carotenoids}

Total carotenoids were evaluated throughout storage time at different chitosan concentrations. Storage time was the most important
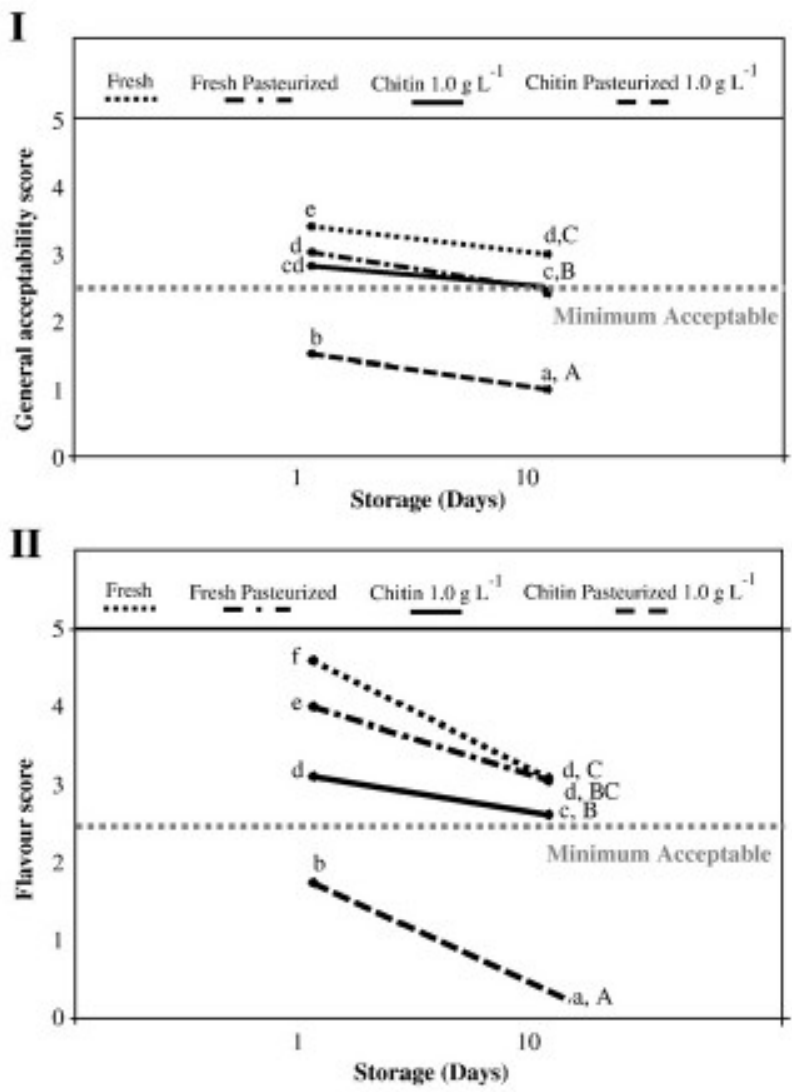

Fig. 14. Response surface methodology for changes in aerobic counts (log CFU mL-1 as a function of chitosan concentration ( $\mathrm{g}$ L-1) and storage time (days) in fresh orange juice packaged and stored at $4{ }^{\circ} \mathrm{C}$
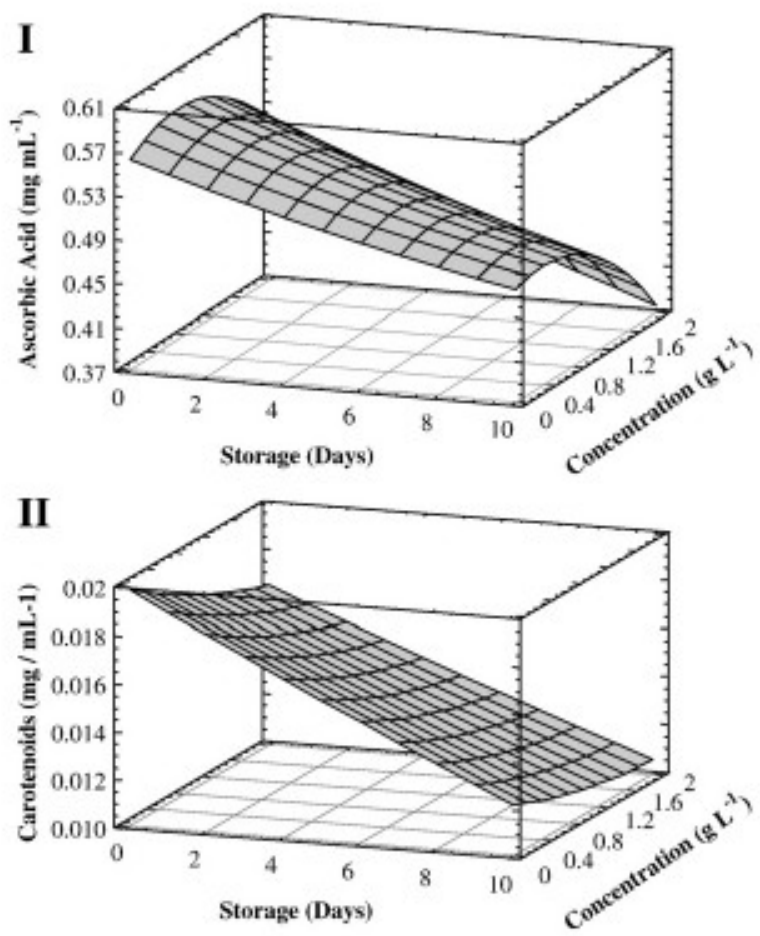

Fig. 15. Response surface methodology for ascorbic acid ( $g \mathrm{~mL}-1)$ as a function of chitosan concentration ( $\mathrm{g} \mathrm{L}-1)$ and storage time (days) in fresh orange juice packaged and stored at $4{ }^{\circ} \mathrm{C}(\mathrm{l})$ and response surface methodo and stored at $4^{\circ} \mathrm{C}(\mathrm{I})$ and response surface methodology for carotenoids $(\mathrm{g} \mathrm{mL}-1)$ as packaged and stored at $4{ }^{\circ} \mathrm{C}$ (II).

factor affecting carotenoid degradation (Fig. 15II). Also, chitosan concentration affected the carotenoid content of the samples, but in a much lower degree as seen in Fig. 15II. The antioxidant effect of chitosan did not protect carotenoids from oxidation over storage time, and these decreased in the same fashion in all the samples over storage time, regardless of chitosan content. The initial reduction of carotenoid due to chitosan addition might be due to a side effect of carotenoid sequestration.

\section{Conclusion}

This paper shows the possible use of chitosan as a natural preservative ingredient to extend the shelf-life of fresh orange juice. Variations in chitosan concentration in the range evaluated ( 0 to $2 \mathrm{~g} \mathrm{~L}-1$ ) were critical in some of the parameters studied, i.e. flavour, ascorbic acid content, browning potential and total microbial load in the extension of the quality of the orange juice, especially in parameters such as browning and reduction of aerobic counts. Higher chitosan concentrations maintained the quality better than lower concentrations from a quality point of view; however, the reduction in vitamin $\mathrm{C}$ due to chitosan addition, associated to the flocculation capacity of chitosan, suggests the use of concentrations below $1 \mathrm{~g} \mathrm{~L}-1$ in order to obtain a balance between quality and nutritional values. Further research on the effect of the deacetylation degree of chitosan in the preservation of orange juice is recommended. Further microbiological studies are recommended to assess the efficacy of chitosan as a natural preservative for orange juice.

\section{Acknowledgements}

The authors would like to thank for the laboratory facilities service at the University Politécnica of Valencia (Rheology and Cryo-SEM) and especially Joaquin Calvo who completed his final year dissertation 
in this project and whose contribution has been essential in the preparation of this manuscript.

\section{References}

Abdullah, A. G. L., Sulaiman, N. M., Aroua, M. K., \& Megat Mohd Noor, M. J. (2007). Response surface optimization of conditions for clarification of carambola fruit juice using a commercial enzyme. Journal of Food Engineering, 81, 65-71.

Alasalvar, C., Al-Farsi, M., Quantick, P. C., Shahidi, F., \& Wiktorowicz, R. (2005). Effect of chill storage and modified atmosphere packaging (MAP) on antioxidant activity,
(a) anthocyanins, carotenoids, phenolics and sensory quality of ready-to-eat shredded anthocyanins, carotenoids, phenolics and sensory quality
orange and purple carrots. Food Chemistry, 89, 69-76.

Ayhan, Z., Yeom, H. Y., Zhang, Q. H., \& Min, D. B. (2001). Flavour, colour and vitamin C retention of pulsed electric field processed orange juice in different packaging retention of pulsed electric field processed orange juice in differen

Bomben, J. L., \& King, C. J. (1982). Heat and mass transport in the freezing of apple tissue. Journal of Food Technology, 17, 615-632.

The, K., Howe, E., Goicoechea, D., Paramanandhan, P., Stockman, R., et al. (2004). The effect of high pressure processing on the microbial, physical and chemical properties of Valencia and $\mathrm{Navel}$ orange juice. Innovative Food Science \& Emerging Technologies, 5, 135-149.

Bruhn, C. (2000). Food labelling: Consumer needs. In J. R. Blanchfield (Ed.), Innovative food sci. food labelling Cambridge: Woodhead Publishing Limited.

Cardello, A. V., Schutz, H. G., \& Lesher, L. L. (2007). Consumer perceptions of foods processed by innovative and emerging technologies: A conjoint analytic study. Emerging Technologies, 8, 73-83.

Chatterjee, S., Chatterjee, S., Chatterjee, B. P., \& Guha, A. K. (2004). Clarification of fruit juice with chitosan. Process Biochemistry, 39, 2229-2232.

Cochran, W. G., \& Cox, G. M. (1957). Some methods for the study of response surfaces. Experimental designs (pp. 12-20). New York: John Wiley and Sons Inc.

Cortés, C., Esteve, M. J., \& Frigola, A. (2008). Colour of orange juice treated by high intensity pulsed lectric fields during refrigerated storage and comparison with pasteurized juice. Food Control, 19, 151-158.

Cortés, C., Esteve, M. J., Rodrigo, D., Torregrosa, F., \& Frígola, A. (2006). Changes of colour and carotenoids contents during high intensity pulsed electric field treatment in orange juices. Food \& Chemical Toxicology, 44, 1932-1939.

Crelier, S., Robert, M. C., \& Juillerat, M. A. (1999). Effect of a high pressure treatment of the texture and enzyme and enzyme activities of selected vegetable. In H. Ludwig (Ed.), Advances in high pressure bioscience and biotechnology (pp. 413-416). Berlin: Springer-Verlag.

Cyanotech Corporation (2001). BioAstin/NatuRose technical bulletin \#015. Kailua-Kona, Hawaii: Cyanotech Corporation.

Del Caro, A., Piga, A., Vacca, V., \& Agabbio, M. (2004). Changes of flavonoids, vitamin C and antioxidant capacity in minimally processed citrus segments and juices during storage. Food Chemistry, 84, 99-105.

Devlieghere, F., Vermeulen, A., \& Debevere, J. (2004). Chitosan: Antimicrobial activity, interactions with food components and applicability as a coating on fruit and vegetables. Food Microbiology, 21, 703-714.

Dunn, J. E. (2001). Pulsed electric field processing: An overview. In G. V. BarbosaCanovas \& Q. H. Zhang (Eds.), Pulsed electric fields in food processing: Fundamental aspects and applications (pp. 1-30). England: Lancaster, PA: Technomic Publishing Company.

Einbu, A., \& Varum, K. M. (2003). Structure-property relationship in chitosan. In T. Priotr (Ed.), Chemical and functional properties of food saccharides (pp. 223).

Fachin, D., Van Loey, A. M., Nguyen, B. L., Verlent, I., Indrawati, \& Hendrickx, M. E. (2003). Inactivation kinetics of polygalacturonase in tomato juice. Innovative Food Science \& Emerging Technologies, 4, 135-142.

FDA (2005). FDA issues nationwide health alert on Orchid Island unpasteurized orange juice. Products recalls, market withdrawals and safety alerts.

juice. Products recalls, market withdrawals and safety alerts.
Fellers, P. J. (1988). Shelf life and quality of freshly squeezed unpasteurized polyethylene-bottled citrus juices. Journal of Food Science, 53, 1699-1702.

Genovese, D. B., Elustondo, M. P., \& Lozano, J. E. (1997). Color and cloud stabilization in cloudy apple juice by steam heating during crushing. Journal of Food Science, 62, 1171-1175.

Grassin, C., \& Fauquembergue, P. (1996). Application of pectinases in beverages. In J. Visser \& A. G. J. Voragen (Eds.), Pectin and pectinases (pp. 453-462). Elsevier Science B.V.

Han, C., Lederer, C., McDaniel, M., \& Zhao, Y. (2005). Sensory evaluation of fresh strawberries (Fragaria ananassa) coated with chitosan-base edible coatings. Journal of Food Science, 70, 172-178.

Helander, I. M., Nurmiaho-Lassila, E. L., Ahvenainen, R., Rhoades, J., \& Roller, S. (2001). Chitosan disrupts the barrier properties of the outer membrane of gram-negative bacteria. International Journal of Food Microbiology, 71, 235-244.

Imeri, A. G., \& Knorr, D. (1988). Effect of chitosan on yield and compositional data of carrot and apple juice. Journal of Food Science, 53, 1707-1709.

Kelebek, H., Canbas, A., \& Selli, S. (2008). Determination of phenolic composition and antioxidant capacity of blood orange juices obtained from cvs. Moro and Sanguimello (Citrus sinensis (L.) Osbeck) grown in Turkey. Food Chemistry, 107, 1710-1716

Khandari, P., Gill, B. S., \& Sodhi, N. S. (2002). Effect of concentration and temperature on the rheology of mango pulp. Journal of Food Science \& Technology, 39, 152-154.

Kilinç, A., Onal, S., \& Telefoncu, A. (2002). Stabilization of papain by modification with chitosan. Turkish Journal of Chemistry, 26, 311-316.

Kimball, D. A. (1991). Citrus processing-quality control and technology. New York: Van Nostrand Reinhold.
Kisko, G., Sharp, R., \& Roller, S. (2005). Chitosan inactivates spoilage yeasts but enhances survival of Escherichia coli O157:H7 in apple juice. Journal of Applied Microbiology, $98,872-880$.

Krebbers, B., Matser, A. M., Hoogerwerf, S. W., Moezelaar, R., Tomassen, M. M. M., \& van den Berg, R. W. (2003). Combined high-pressure and thermal treatments for processing of tomato puree: evaluation of microbial inactivation and quality

Knorr, D. (1984). Use of chitinous polymers in food - A challenge for food research and development. Food Technology, 38, 85-97.

Martín-Belloso, O., \& Elez-Martínez, P. (2005). Food safety aspects of pulsed electric fields. In D. W. Sun (Ed.), Emerging technologies for food processing (pp. 183-217).

Meléndez-Martínez, A. J., Vicario, I. M., \& Heredia, F. J. (2003). Application of tristimulus colorimetry to estimate the carotenoids content in ultrafro

No, H. K., Meyers, S. P., Prinyawiwatkul, W., \& Xu, Z. (2007). Applications of chitosan for improvement of quality and shelf life of foods: A review. Journal of Food Science, 72 87-100.

Ohlsson, T. (1994). Minimal processing-preservation methods of the future - An overview. Trends in Food Science \& Technology, 5, 341-344.

Park, P. J., Je, J. Y., \& Kim, S. K. (2004). Free radical scavenging activities of differently deacetylated chitosans using an ESR spectrometer. Carbohydrate Polymers, 55, $17-22$

Prashanth, K. V. H., \& Tharanathan, R. N. (2007). Chitin/chitosan: modifications and their unlimited application potential - An overview. Trends in Food Science \& Technology, 18, 117-131.

Quadir, M., Hickey, M., Boulton, A., \& Hoogers, R. (2006). Accumulation of total soluble solids in processing tomatoes. Acta Horticulturae, 724, 97-102.

Rapisarda, P., Bellomo, S. E., \& Intelisano, S. (2001). Storage temperature effects on blood orange fruit quality. Journal of Agricultural \& Food Chemistry, 49, 3230-3235.

Riccardo, A., \& Muzzarelli, A. (1977). Chitin. London: Pergamon Press Ltd.

Rivas, A., Rodrigo, D., Martínez, A., Barbosa-Cánovas, G. V., \& Rodrigo, M. (2006). Effect of PEF and heat pasteurization on the physical-chemical characteristics of blended orange and carrot juice. Food \& Science Technology, 10, 1163-1170.

Rodrigo, D., Arranz, J. I., Koch, S., Frigola, A., Rodrigo, M. C., Esteve, M. J., et al. (2003). Physicochemical characteristics and quality of refrigerated Spanish orange-carrot juices and influence of storage conditions. Journal of Food Science, 68, 2111-2116.

Rodrigo, D., Barbosa-Canovas, G. V., Martínez, A., \& Rodrigo, M. (2003). Pectin methyl esterase and natural microbial flora of fresh mixed orange and carrot juice treated with pulsed electric fields. Journal of Food Protection, 66, 2336-2342.

Rosenthal, A., \& Silva, J. L. (1997). Foods under pressure. Food Engineering, 14, 37-39.

Roller, S., \& Covill, N. (1999). The antifungal properties of chitosan in laboratory media and apple juice. International Journal of Food Microbiology, 47, 67-77.

Rungsardthong, V., Wongvuttanakul, N., Kongpien, N., \& Chotiwaranon, P. (2006). Application

Sapers, G. M. (1992). Chitosan enhances control of enzymatic browning in apple and pear juice by filtration. Journal of Food Science, 57, 1192-1193.

Shahidi, F., Arachchi, J. K. V., \& Jeon, Y. J. (1999). Food applications of chitin and chitosans. Trends in Food Science \& Technology, 10, 37-51.

Shi, J., \& Maguer, M. L. (2000). Lycopene in tomatoes: chemical and physical properties affected by food processing. Critical Reviews in Food Science \& Nutrition, 40, 1-42.

Shaw, P. E., \& Moshonas, M. G. (1991). Ascorbic acid retention in orange juice stored under simulated consumer home conditions. Journal of Food Science, 56, 867-868.

Shook, C. M., Shellhammer, T. H., \& Schwartz, S. J. (2001). Polygalacturonase, pectinesterase, and lipoxygenase activities in high-pressure-processed diced pectinesterase, and lipoxygenase activities in high-pressure-process
tomatoes. Journal of Agricultural and Food Chemistry, 49, 664-668.

Sin, H. N., Yusof, S., Sheikh Abdul Hamid, N., \& Rahman, R. A. (2006). Optimization of enzymatic clarification of sapodilla juice using response surface methodology. Journal of Food Engineering, 73, 313-319.

Soliva-Fortuny, R. C., \& Martín-Belloso, O. (2003). New advances in extending the shelflife of fresh-cut fruits: A review. Trends in Food Science \& Technology, 14, 341-353.

Soto-Peralta, N. V., Muller, H., \& Knorr, D. (1989). Effects of chitosan treatments on the clarity and color of apple juice. Journal of Food Science, 54, 495-496.

Tran, T.T.M., 2001. Ultraviolet sterilization of orange juice. MSc. Thesis. The University of Auckland, Auckland, New Zealand. pp. 1-2.

Tran, M. T. T., \& Farid, M. M. (2002). Ultraviolet disinfection of carrot juice. Proceedings of the 9th annual New Zealand Engineering and Technology Postgraduate Conference (pp. 169-175). Auckland, New Zealand: Auckland University Technology

Vikram, V. B., Ramesh, M. N., \& Prapulla, S. G. (2005). Thermal degradation kinetics of nutrients in orange 14 juice heated by electromagnetic and conventional methods. Journal of Food Engineering, 69, 31-40.

Viňa, S. Z., \& Chaves, A. S. (2006). Antioxidant responses in minimally processed celery during refrigerated storage. Food Chemistry, 94, 68-74.

Watada, A. E., Ko, N. P., \& Minott, D. A. (1996). Factors affecting quality of fresh-cut horticultural products. Postharvest Biology \& Technology, 9, 115-125.

Wang, S. L., \& Chang, W. T. (1997). Purification and characterization of two bifunctiona chitinases/lysozymes extracellularly produced by Pseudomonas aeruginosa K-187 in a shrimp and crab shell powder medium. Applied \& Environmental Microbiology, 63, 380-386.

Yalpani, M., Johnson, F., \& Robinson, L. E. (1992). Antimicrobial activity of some chitosan derivatives. In C. J. Brine, P. A. Sandford, \& J. P. Zikakis (Eds.), Advances in chitin and chitosan (pp. 543-555). London: Elsevier Applied Science.

Zheng, L. Y., \& Zhu, J. F. (2003). Study on antimicrobial activity of chitosan with different molecular weights. Carbohydrate Polymers, 54, 527-530. 